\title{
Innovative Practice and Application of Piano Teaching from the Perspective of New Era
}

\author{
Dai Xiaoqin \\ Sichuan University of Science and Engineering Conservatory of Music, Sichuan, China, 643000
}

Keywords: new period; piano teaching method; thinking

Abstract: The author of this paper analyzes the existing piano education mode, expounds the diversified teaching mode, and discusses the application of the diversified teaching mode in piano teaching. At present, the professional music education colleges in China have formed a piano teaching system with perfect structure, distinctive features and complete teaching facilities. Many well-known professional music education institutions in China are constantly updating their teaching concepts, improving their teaching models, and making important contributions to the promotion of piano culture and the development of piano teaching. In order to effectively improve the performance level of professional piano students and the quality of piano teaching, professional music education institutions have carried out a series of teaching reforms and teaching attempts. Many schools promote the improvement of teaching level by formulating technical and artistic standards at all stages of piano teaching, implementing a two-way selection system for teachers and students, and rationally planning examination models. At the same time, they pay attention to the performance and teaching of Chinese excellent piano works, and actively promote Chinese piano works and The promotion and promotion of piano culture.

\section{Introduction}

Piano teaching is an important basic subject in the entire music education system. Under the premise of vigorously promoting quality education and comprehensive development in the country, piano education has received extensive attention from all walks of life. For a long time, piano teaching mostly adopts one-on-one individual teaching mode, which is designed to meet the learning needs of students and effectively improve the teaching level. This teaching mode also depends on the characteristics of piano teaching. With the gradual popularization of piano art, the number of students who choose to study piano courses has also increased. The drawbacks of this singular teaching model have been fully demonstrated, which has a negative impact on the level of piano teaching and the improvement of students' performance skills.

\section{Existing piano education mode}

The traditional piano teaching mode piano course is generally two years, one class per class, 1-4 students per class; the course content is generally finger-based exercises, Etudes, polyphony, sonatas and music; teaching methods are mostly The teacher-apprentice teaching mode. Such a 
teaching system has become the stereotype of piano teaching in China. With the continuous development and promotion of piano teaching, the students who are studying piano majors are growing day by day. The traditional individual teaching mode has a great contrast between the strength of teachers and the number of students, which leads to a decline in the quality of teaching. The traditional teaching mode pays attention to the cultivation of students' basic practice and performance ability, neglects the cultivation of students' understanding ability and creativity, and shows unity in curriculum setting, teaching mode and assessment mechanism, which is difficult to effectively stimulate students' interest in learning. It is not conducive to students' aesthetic experience and aesthetic imagination, which affects the quality of piano teaching.

\section{Overview of Diversified Teaching Models}

In the narrow sense of diversity, in the social sciences, different races, ethnic groups, religions, and social groups independently develop their own culture or interests under the common civilized or social framework. The pluralism in the diversified teaching model refers to an academic viewpoint, originally proposed by the famous American educator and philosopher Dewey, and has set off a multicultural trend of thought in the world. With the continuous deepening of the teaching reform process in China, diversified academic views have been widely used in the teaching reform ideas and teaching activities. The piano score is shown below.



Fig.1 Piano score

The diversified teaching mode refers to the exploration of teaching mode in the teaching and learning activities according to the teaching training objectives, the teaching curriculum and the students' comprehensive development needs, mainly manifested in the diversification of teaching modes, the diversification of teaching content and the diversity of teaching methods. Turn. The diversified teaching mode is a multi-disciplinary system that comprehensively cultivates students' knowledge, abilities and qualities. It fully demonstrates the diversity of teaching content, processes, means, methods and methods. The construction of diversified teaching mode is the inevitable requirement of the rapid development of society and the quality education system for teaching activities. It is the objective need to cultivate students' comprehensive quality and students' all-round development, and it is also the multi-level and multi-type development needs of music education [1].

\section{Application of Diversified Teaching Mode in Piano Teaching}

Piano teaching refers to the piano music such as piano practice music and piano music played regularly and scientifically under the guidance of professional teachers, and then achieves the 
purpose of improving the piano playing ability and playing skills. Applying the diversified teaching mode to piano teaching activities is not only a new teaching reform attempt, but also can change the current single teaching mode, which is of great significance to the development and promotion of piano teaching.

The teaching process of the piano is a process that requires teachers and students to cooperate and cooperate closely. From the basic playing technique in the early stage of learning, to the more mature piano works with certain difficulty, and showing their understanding of music for teachers and students. It is a long and difficult teaching process. Under the background of stricter requirements for music talents in the society, it is necessary to establish a piano teaching system with teaching characteristics and relatively perfect [2].

\subsection{Applying Diversified Teaching Mode to Teaching Music Theory Knowledge}

Piano teaching is a teaching activity to cultivate students' comprehensive ability. It is a teaching process in which students learn piano playing skills and play piano works under the guidance of teachers. The theoretical knowledge in piano teaching is usually more abstract, and it is difficult for students to form a specific perceptual knowledge in a relatively short period of time, which brings difficulties to students' understanding of piano works. Applying a diversified teaching model to transform abstract theoretical knowledge into specific time activities can help students analyze and understand piano works while exercising students' performance skills. In the basic music theory teaching, the explanation of theoretical knowledge such as chord function and chord progression can be transformed into concrete practical activities, making abstract theoretical knowledge into sound notes, enhancing students' sensory understanding of piano works and enhancing students. The ability to analyze and understand piano works. Piano teaching management mode as shown below.

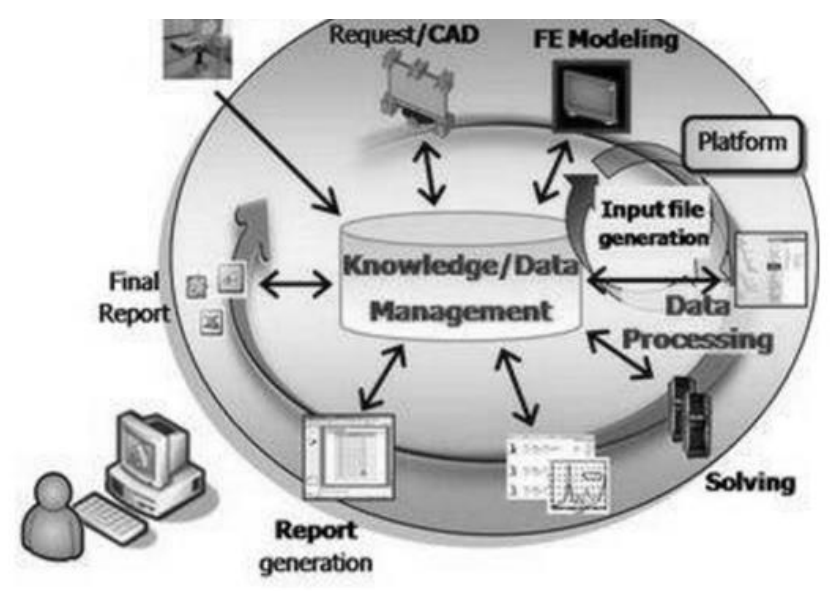

Fig.2 Piano teaching management mode

\subsection{Application of Diversified Teaching Models and Students' Understanding and Creativity}

In the traditional piano teaching mode, teachers pay more attention to the exercise of students' strength, speed and expressiveness, ignoring the students' ability to understand and create the artistic connotation of piano works. Applying a diversified teaching model enables students to play on the basis of understanding the connotation of piano works, in order to fully exert their playing skills, express the artistic connotation of piano works, and make the performance more expressive. The playing of piano works is a process of secondary creation. By analyzing and understanding the works, I express my artistic feelings on the basis of the original works. In the process of piano teaching, the teacher can guide the students to deepen their understanding of the piano works by 
analyzing the music speed, music form and musical mood of the works, and on this basis, express the individual artistic creation ability [3].

\subsection{Applying a diversified teaching model for impromptu accompaniment teaching}

Piano impromptu accompaniment teaching is a teaching project to cultivate students' comprehensive ability and collaborative spirit. The traditional piano teaching mode often ignores the importance of piano impromptu accompaniment teaching, which leads to some poems with better piano performance level facing the improvisation accompaniment. It appears extremely unfamiliar, affecting the performance of the performance level and the effect of piano teaching. Applying the diversified teaching mode to set up the curriculum, and gradually constructing a comprehensive and perfect teaching system. On the basis of cultivating students' piano performance skills, strengthening the training of impromptu accompaniment and consolidating the knowledge of keyboard and music theory, it is of great significance to improve the piano teaching water. . In the selection of teaching materials, we should adhere to the concept of diversification, learn from a variety of teaching materials, and cultivate students' comprehensive ability. The piano teaching materials under the teaching reform system have strong interest and knowledge, but lack systematic skills. The works of Cirny contain systematic training of performance skills. In piano teaching, the two can be effectively combined to ensure students' comprehensive skills. Ability to exercise and improve [4].

\subsection{Application of diversified teaching mode for teaching skills}

Piano art mainly expresses its artistic charm through high-difficult playing skills and skillful playing techniques. Good playing skills are an important basis for piano players to express their works and interpret their emotions. Neglecting the systematic training of playing skills can not satisfy the speed and intensity required for piano works, and can not express the content, emotion and mood of the works well. Therefore, in the process of piano teaching, the application of diversified teaching mode for students to choose a variety of targeted skills training materials, according to the degree of mastery of the students to develop a variety of teaching methods, fundamentally strengthen the training of playing skills, so that students The mastery of the playing skills can meet the performance requirements of different piano works.

\section{Summary}

To sum up, the active application of the diversified teaching mode in piano teaching is of great significance for cultivating high-quality talents with innovative spirit and practical ability to construct a teaching system that adapts to the development of the times, enhance the overall level of teaching and improve the quality of teaching.

\section{Acknowledgement}

Source: new institution reform and Development Research Center Project Name: training of Applied Talents in piano accompaniment of music majors in Universities

Project number: XJYX2017B04

\section{References}

[1] Regina Antunes Teixeira dos Santos, Cristina Capparelli Gerling, Álvaro Luiz de Bortoli. Implications of time adjustments at micro, macro and meso levels in undergraduate and graduate piano students' performance [J]. Music 
Education Research, 2017, 19(2).

[2] Anchen Froneman. 'The sight and sound of fireworks' - embodied interactions within piano performance gestures [J]. South African Theatre Journal, 2018, 31(1).

[3] Lawrence M. Parsons, Justine Sergent, Donald A. Hodges, Peter T. Fox. The brain basis of piano performance [J]. Neuropsychologia, 2004, 43(2).

[4] Hidehiro Nakahara, Shinichi Furuya, Peter R. Francis, Hiroshi Kinoshita. Psycho-physiological responses to expressive piano performance [J]. International Journal of Psychophysiology, 2010, 75(3). 